\title{
One step forward, two steps back: transitions between home, pre- primary and primary education in rural India
}

\author{
Benjamin Alcott,${ }^{*}$ Manjistha Banerji, ${ }^{,}$Suman Bhattacharjea,${ }^{,}$Mansi
}

Nanda, ${ }^{b}$ and Purnima Ramanujan ${ }^{b}$

"Faculty of Education, University of Cambridge, 184 Hills Road, Cambridge CB2 $8 P Q$, United Kingdom

${ }^{\circ}$ ASER Centre, B 4/54 Safdarjung Enclave, New Delhi 110 029, India

*bma27@cam.ac.uk

\section{Acknowledgements}

All data used in this paper was collected as part of the India Early Childhood Education Impact study (IECEI), which was conducted by ASER Centre, New Delhi, and the Centre for Early Childhood Education and Development at Ambedkar University Delhi in partnership with UNICEF. The writing of this paper was supported by the British Association for International and Comparative Education's (BAICE) Seedcorn Fund, and benefitted from the feedback of attendees at a seminar hosted by the University of Cambridge's Research for Equitable Access and Learning Centre. The authors would like to thank the partners, field investigators, families and children who made this study possible.

Word count: 7,064 (words) $+1,150$ ( 2.5 pages of tables \& figures $)=8,214$ words 


\title{
One step forward, two steps back: transitions between home, pre- primary and primary education in rural India
}

\author{
A growing evidence base highlights the value of high-quality early childhood \\ education (ECE) to children's cognitive and social development. However, far \\ less is known about how families and children, especially in developing \\ countries, participate in ECE or how these participation patterns reflect \\ families' thinking and decision-making. This paper utilises a mixed-methods \\ approach to analyse longitudinal household survey and interview data (on \\ 7,336 and 180 children, respectively) from the India Early Childhood \\ Education Impact study. Our results indicate that children's participation \\ trajectories in the early years (age 4 to 8 ) do not reflect the age or grade norms \\ specified by national educational policies. And, far from being linear, \\ children's educational pathways entail considerable back and forth between \\ home, preschool and school. We argue that these trajectories reflect both poor \\ implementation of national norms as well as an inadequate understanding \\ among both parents and service providers of how best to support young \\ children's cognitive development.
}

Keywords: Early-childhood education; participation; India; Assam; Rajasthan; Telangana

\section{Introduction}

The increasing emphasis on early childhood education (ECE) in educational policy debates globally (UNESCO 2015, Goal 4, Target 2) is well founded (for a review, see Woodhead et al. 2014). Within the fields of neuroscience and psychology, there is widespread agreement that the developmental period of infancy is crucial to 
brain development (Karoly 1998; Young and Richardson 2007) and the subsequent acquisition of competencies (Kohlberg 1968; Ramey and Ramey 1998), meaning that additional learning during these stages can have long-lasting effects on cognitive and academic development (Campbell et al. 2001; Shore 1997). Within the field of economics, a common rationale, stemming from human capital theory (Becker 1980), is that early cognitive development shapes subsequent opportunities throughout the lifespan (Cunha et al. 2006; Heckman 2011).

These conceptualisations are backed by empirical evidence from developing countries, which show that high quality ECE (e.g. through structured sessions delivered by trained staff) can boost development not only in children's cognitive and social skills, but also long-term educational, health, economic and labour market outcomes (Engle et al. 2011; Nonoyama-Tarumi, Loaiza, and Engle 2009; Rao et al. 2013). But while there is already clear evidence on the value of good ECE, and policy in many countries reflects this knowledge, we know relatively little about the pathways young children in developing contexts actually take between home, ECE, and primary education through the early years, and how these reflect families' thinking about the importance of ECE. While policymakers may mandate clear transitions at specific developmental stages, the extent to which such norms are manifested in households' decision-making is less clear.

This paper aims to inform research and policy debates on early childhood education by shedding light on whether, when, and why households in rural India make use of ECE opportunities for their young children. We do this with mixedmethods analysis of a unique longitudinal dataset conducted in three states: Assam, Rajasthan, and Telangana. With access to both quantitative and qualitative data, we are able to both identify distinctive patterns between states with regard to the 
pathways children take as well as explore how these differences reflect families' thinking and decision-making.

\section{Prior evidence on early childhood education in India}

A growing body of evidence from India make clear that children's learning outcomes are far below expected levels, and have not improved over the past decade (ASER Centre 2015). As with many countries, conditions are most severe amongst children from disadvantaged households (see, for example, Borooah 2012; Kingdon 2007; Rolleston and James 2015; Woodhead, Dornan, and Murray 2013). Across rural India, for example, fewer than $25 \%$ of poorer children aged $11-13$ are in school and have learned the basics, just half the proportion of wealthier children (Rose et al. 2017).

Poor learning levels are apparent from the very first years of school: for example, in third grade $58 \%$ of children are still unable to read a Grade 1 level text (ASER Centre 2017).Keeping up with the curriculum right from the start is important: only around one in 10 children who lack basic literacy or numeracy skills are able to acquire them after an additional year of schooling (Bhattacharjea, Banerji, and Wadhwa 2011; Educational Initiatives 2010; Pritchett and Beatty 2015), and the gap between curriculum expectations and children's abilities only widens over time. The importance of the early years is further corroborated by the fact that dropout rates in India have been higher in Grades 1 and 2 than in later primary school grades (Mehta 2007; Reddy and Sinha 2010), indicating the precariousness of the transition from home/preschool to Grades 1 and 2.

The Indian government has a long history of providing early childhood development services at scale via the Integrated Child Development Services (ICDS), established in 1975. Globally, ICDS was among the world's first attempts to provide a 
nationwide early childhood development programme (Woodhead et al. 2014) and remains one of the largest such programmes in the world. However, ICDS has tended to prioritise nutrition, sanitation, and health more broadly (Ali 2015; Programme Evaluation Organisation (PEO) Planning Commission 2011), and the government has acknowledged that the programme's educational component is 'particularly deficient in quality' in some parts of the country (Government of India 2013b, 16). In other words, ICDS has focused more on establishing elements of wellbeing that are essential for children to learn, rather than focusing explicitly on providing opportunities to learn.

Policy attention towards the education component of early childhood development has increased in recent years, partly as the result of efforts from supranational agencies to highlight its importance (UNESCO 2015). The National Policy on Early Childhood Care and Education was approved in 2013 and a national curriculum for ECE was released soon afterwards, although its implementation on the ground has been slow. The policy framework in the domain of school education largely ignores children below school-going age: the 2009 Right of Children to Free and Compulsory Education (RTE) Act guarantees eight years of free education for children in the age group 6-14, recommending only that 'the appropriate Government may make necessary arrangement for providing free pre-school education' for children until the age of 6 (Government of India 2009, Art.11). Hence, despite the recent policy changes, government provision of ECE in India falls into a grey area between a focus on more immediate health and nutrition priorities in early childhood development and a focus on education that begins only from primary school entry. According to data from the Ministry for Women and Child Development for 2014-15, ICDS anganwadis ('courtyard centres') reached over 100 million children 
aged between zero and six (Government of India 2017), of which more than 36 million were in the ECE age group of 3-6 years - more than a third of all children in this age group (Registrar of India 2011). The true extent of ECE in India though is greater still, as many children are served by a growing number of private preschool providers, many of which offer English-medium classes imitating formal primary schooling (Streuli, Vennam, and Woodhead 2011; Singh and Bangay 2014). Even in rural areas, while most 4-year olds attend anganwadis, a fifth attend private preprimary centres (ASER Centre 2017).

Despite the government's stated intention of harmonising services across all ECE providers (Government of India 2013a), no comprehensive list of all ECE providers exists in India. Research evidence on Indian children's participation in ECE and its value is also limited. Much of the recent evidence available comes from crosssectional data from Jammu and Kashmir (Arora et al. 2006, 2007, 2011) and longitudinal data from Andhra Pradesh (Vennam and Komanduri 2009; Streuli, Vennam, and Woodhead 2011; Woodhead et al. 2009). Findings by Arora et al. (2007, 2011) suggest that children who attend anganwadis in Jammu and Kashmir may on average have greater levels of cognitive development than those who do not, although this should not be misconstrued as a causal effect of anganwadi attendance. Additionally, a few experimental studies have demonstrated the potential for ECE participation to have substantial benefits for children's cognitive development, for example via parenting training (Nair et al. 2009), oracy programmes (Piramal and Law 2001), or improved staff training and funding (Ade et al. 2010).

Research on conditions in Andhra Pradesh (now Andhra Pradesh and Telangana), using data from the longitudinal Young Lives survey, has added to our understanding of the non-uniform nature of ECE participation. Perhaps most 
importantly, they find that not only ECE participation, but also the type of ECE provider attended, is socially stratified (Streuli, Vennam, and Woodhead 2011). Simply put, surveyed families perceived private providers as being of higher quality, especially those purporting to offer English-medium instruction (Streuli, Vennam, and Woodhead 2011; Singh and Bangay 2014). And since private ECE providers tend to charge fees, it is typically, though not exclusively, more advantaged families who send their children to these providers, thus mirroring trends in primary and secondary schooling (Alcott and Rose 2015; Woodhead, Frost, and James 2013). Further, where households only have the ability to send some children to private ECE providers, boys tend to be favoured over girls (Streuli, Vennam, and Woodhead 2011). While the Young Lives study has enabled important studies exploring parental choice and perceptions in ECE, its insights on ECE are restricted to coverage of a single state in India. Findings from a more recent multi-state longitudinal study corroborate the importance of gender and socioeconomic status, while also emphasising geographic differences in conditions (Authors).

\section{Focus of this paper}

In summary, despite the recent development of a national policy and curriculum framework, ECE in India is still far less regulated than the school system. India's government has ensured that almost all citizens have access to at least one government ECE provider (anganwadi), and the proliferation of private provision has led to multiple institutions operating even in rural areas (Ashley et al. 2014; Authors). Yet, little is known about how households navigate this highly unregulated environment. And while we have some sense of the degree of inequality in ECE participation across India, we know far less about the timing of enrolment at the different education stages across different contexts in India. 
Our analysis uses the datasets generated by the India Early Childhood Education Impact (IECEI) study to offer a number of advancements on prior research. First, we provide analysis based on data from three states in India - Assam, Rajasthan, and Telangana, which differ in terms of geographical conditions and socioeconomic development indicators. This enables us to examine whether observed trends reflect national level patterns or are specific to individual states. Second, the analysis is based on data from a large sample of 7,336 children, making it more plausible that any patterns identified are representative of broader trends. Third, the analysis is based on longitudinal data: sampled children were tracked in eleven waves of data collection over a four-year period, from age four to eight. These factors enable us to consider participation in, and transitions across, ECE and primary school as a process that is dynamic and varied, rather than static and uniform, and to observe how households' ECE opportunities and decision-making evolve over time.

We make use of these strengths to explore the transitions that children make, both within ECE and into primary school grades. More specifically, we explore transitions in terms of children's progress. By progress, we mean the timing of children's movements, first into ECE facilities and then into primary schools, and the degree to which this maps onto the timing mandated by national education policy, e.g. that at age 5 children should be in some form of pre-primary provision (Government of India 2009). We articulate these interests through the following research questions: 
1. To what extent do children progress into pre-school and then primary school 'on time', as per national policy norms?

2. In what ways does the timing of these transitions reflect parents' thinking about early childhood education?

\section{Methods}

We use a mixed-methods approach to answer these research questions. More specifically, we consider our analysis to represent a blended research design, wherein we afford two different methods equal status to explore different aspects of the same phenomena (Greene 2007). To identify patterns in children's progress into preprimary and then primary school (research question 1), we analyse a longitudinal household quantitative dataset. To explore the thinking and decision-making at the household level that underpin these broader patterns (research question 2), we use qualitative interview data from households purposively sampled to provide perspectives from a diversity of household conditions. The aim is that by building on the distinctive strengths of each approach, the methods provide real complementarity (Small 2011) in developing our knowledge of ECE participation in India.

\section{[Figure 1]}

For research question 1, we undertake descriptive quantitative analysis of 11 waves of survey data from the India Early Childhood Education Impact (IECEI) study, which followed a cohort of children in the states of Assam, Rajasthan, and Telangana over a four-year time frame (September 2011-December 2015) . Our analysis focuses on the 7,336 children for whom we have participation information for each of the 11 survey waves. Summary statistics for this sample is presented in Table 1. 
Our analysis of the survey data focuses on whether children were participating in an educational institution on the day of each survey wave and, if participating, the level of the educational institution (i.e., pre-primary or primary). Information on children's participation was triangulated from three sources: parental reports, institutional records, and surveyors' direct observations. Thus "participation" as defined in this study includes both "official" or "formal" enrolment as well as "unofficial" or "informal" participation because children were often found to be going to an institution (ECE centre or school) without being formally enrolled, and/or enrolled in one institution but attending another.

\section{[Table 1]}

To explore household decision-making processes behind sampled children's participation trajectories (research question 2), we analyse parent interviews undertaken within the IECEI study at the completion of all 11 waves of the quantitative survey. Fieldwork for the qualitative component was conducted in a total of 12 sampled villages (four per state), within which semi-structured interviews were conducted with parents of 180 children who took part in the quantitative survey - 60 in Assam, 58 in Telangana and 62 in Rajasthan. In cases parents of sampled children were unavailable, the available primary caregiver or guardian was interviewed. Data from the quantitative survey was used to inform the selection of both villages and children, with the aim of ensuring a diverse sample in terms of village, household, and child characteristics.

Interviews focused largely on the reasons for sending the sampled child to the institution(s) she or he attended over the previous five years, and what the parents felt the child had gained from the experience. Given that the interviews addressed actions taken several years in the past, the analytical approach sought primarily to identify the 
kinds of considerations parents discussed - and equally, those that were not mentioned. Interviews were conducted in either the state language or the local dialect, as appropriate. All interviews were then recorded and transcribed verbatim into English before analysis.

The embedding of the qualitative inquiry within preliminary findings from the survey data allows us to generate insights that sharpen our understanding of household decision-making and choice. We use the thematic analytical approach (Braun and Clark 2006) to analyse data from these interviews, focusing on two major areas of inquiry: reasons for choice and experience in pre-primary and school. Interviews were first coded inductively and thereafter relevant codes were clustered into mutually compatible categories. This process was iterative and involved delimiting both the themes as well as the codes up to a point of thematic and coding saturation.

\section{Limitations}

This study faces several limitations common to longitudinal research designs. Regarding the quantitative analysis, as with most studies with multiple survey waves (Allison 2012), IECEI is prone to considerable sample attrition. This occurred primarily because enumerators could not locate a child during a particular wave, either because the child was out of the village on the day of the survey or, in some cases, because the family had migrated from the village for a certain period of time. Consequently, whereas the first wave sampled 11,828 children, 7,336 of these children participated in all 11 survey waves. Given that our focus is on how children's participation changed during the full survey, for our analysis we concentrate on this restricted sample of 7,336 children. By definition, it is not possible to know whether those participating in all 11 waves differed on unobservable characteristics. However, 
analysis on observable characteristics from the first survey wave suggest at least a reasonable degree of comparability between the groups: there was no statistically significant difference (at the 0.05 level) between the two samples in either caste or household wealth, indicating that children from marginalized economic and social backgrounds were not more likely to have been left out across survey waves.

Regarding the qualitative analysis, the retrospective nature of the interviews means that parents could encounter difficulties in recalling their perspectives and decision-making processes. Since interviews were conducted at the end of the study, in some instances (i.e., those relating to survey wave 1) parents would have been asked about their children's participation four years earlier. In an effort to circumnavigate this challenge, interviewers drew on information collected during the survey waves in order to prompt parents' memories and focus the discussion on concrete events during the past years. For example, in cases where children had jumped ahead a grade, interviewers asked parents the following questions:

- After being in [institution name], [child] moved to [institution name] and joined class [number]. Can you tell me about this change?

- Why did [child] shift grades when s/he changed school?

- Why did you select this particular school instead of the other options available to you in the village?

- What has [child] experience been at the school? Does s/he like going to school? Did s/he face any difficulties?

Beyond these methodological concerns, a more conceptual challenge relates to what it means to progress through pre- and primary school in India 'on time'. Since education is a concurrent subject under the Indian constitution, state and national 
policies can differ from one another. One such discrepancy relates to the schoolstarting age: national policy dictates that at age 5 children should be in some form of pre-primary provision (Government of India 2009), but Assam, Rajasthan, and Telangana all allow entry into Grade 1 at age 5, as do 27 of India's 36 states and Union Territories (Government of India 2014). Thus, it is possible for children to be both progressing 'on time' according to national policy and not according to state policy, and vice versa.

As specified in our research questions, we focus on progress according to national policy norms, though we will acknowledge instances of potential disparities with state norms. We thus define progress according to the 2009 Right of Children to Free and Compulsory Education (RTE) Act, which mandates a no-detention policy through the elementary education stage (grades 1 through 8 ) and defines age-based criteria for enrolment in specific grades. At ages 4 and 5, children should be in preprimary education. At age 6 children should be enrolled in grade 1, and they then are expected to progress into the next grade in each subsequent academic year, such that they are in grade 2 at age 7 , grade 3 at age 8 , and so on.

Academic calendars add a further degree of complexity: Assam, Telangana, and Rajasthan begin the school year in January, June, and July, respectively. This analysis also accounts for the academic calendar in each state We account for this in each state by grouping children's expected progress according to where their month of birth falls in relation to the academic year; for example, since the school year in Assam begins in January, those children born in December should enter school one school year before those born a month later, in January. 


\section{Findings 1: To what extent do children progress into pre-school and then} primary school ‘on time', as per national policy norms?

Only a third of children progress through pre-primary and early primary school 'on time'.

Figure 2 outlines the percentage of children in each state whose progress is 'behind', appropriate, or 'ahead' of track over time. For example, following the school year in which children turn 6 , those who are in grade 1 are in the appropriate grade for age; those who are not participating in any educational institution, are in anganwadi or other ECE classes are 'behind'; and those who are in grade 2 or higher are 'ahead'. The following school year, children who are in grade 2 are in the appropriate age for grade, and so on. Survey waves are depicted in the graphs according to average child age at the given survey point. The charts highlight that in each state a substantial percentage of children are 'behind' or 'ahead' of track for most of the pre-primary and primary cycle.

\section{[Figure 2]}

At the first survey wave (average child age 4.2 years), almost $100 \%$ of children in Assam are in the appropriate grade for age, meaning that they are attending ECE centres, with Telangana also close to $100 \%$. In contrast, nearly a quarter of children in Rajasthan are 'behind' track, meaning they are not participating anywhere. Another peculiarity is that around $20 \%$ of children in Rajasthan are 'ahead' of track, meaning that they are already attending primary school at age 4 .

Despite state laws permitting entry into primary school at age 5, at average age 5.2 years, almost all children in Assam remain in the appropriate grade for age with respect to RTE norms, i.e. participating in ECE. In contrast, close to a half of children 
in both Telangana and Rajasthan are 'ahead', indicating that state norms permitting earlier entry into primary school matter far more in these states.

The pattern in Assam changes considerably though during the purported primary school years. At average age 6.2 years, when RTE norms expect children to be in grade 1, more than a quarter of children in Assam have fallen 'behind', suggesting they are spending additional years in ECE; the proportion of 'behind' children increases further still, covering more than half of children by age 8.2 years. In Telangana and Rajasthan, on the other hand, from age 6 onwards a substantial percentage of children are present in each of the three categories: appropriate grade for age, 'behind', and 'ahead'. At average child age 8.2 years, in Rajasthan approximately a third of children are in each of the three categories and in Telangana a quarter are 'behind' track, roughly $30 \%$ 'on' track and remaining $40 \%$ 'ahead' of track. While state norms of earlier school-entry age can explain why a large proportion remain 'ahead', those who are behind are conforming neither to national nor to state policy norms.

To summarise, between age 4 and 8 only a minority of children progress through pre-primary and primary education in the appropriate grade for age as per national norms. However, the dynamics of these patterns vary across states. In Assam, while children are in the appropriate grade for age early on, many fall 'behind' in later years. In other words, it appears that children in Assam are attending ECE for longer than stipulated in RTE norms, leading to delayed entry into primary education. In contrast, Rajasthan and Telangana are characterised by many children entering primary school at an early age, as indicated by the large proportion of children who are 'ahead' of track even by age 5. Still, quite a number of children in both states fall 'behind', suggesting prolonged stays in ECE or slow movement through the primary 
grades, such that by age 8 in both states there are near equal shares of children in the appropriate grade for age, 'behind', and 'ahead'.

[Table 2]

These observations are confirmed in Table 2, which shows the proportion of children who have participated in pre-primary and the proportion of children who have already participated in primary at average age five (wave three). By this age, as per RTE norms, all children should have had some pre-primary education but should not yet have entered primary school. As Table 2 shows, these policy norms are not followed in practice. In Rajasthan, a fifth of children have not participated in preschool by age five, while half have already begun primary schooling. Telangana has a similar pattern, albeit with fewer children not having participated in pre-primary (8\%). The trends in Rajasthan and Telangana reflect state norms on age and school entry, which allow children to join primary school at age 5. Nevertheless, it is noteworthy that in both states, substantial proportions of children have no pre-primary education at age 5. Of the three states, it is only in Assam that most children are at the expected stage at age 5 (i.e., having had some participation in pre-primary education, but none in primary).

\section{Most children are either sent back, repeat, or jump a grade.}

It is plausible that even if children enter primary school earlier or later than recommended by RTE, they subsequently make smooth, linear progress across grades (i.e., moving from grade 1 to grade 2 after a year, from grade 2 to 3 after another, and so on). RTE's no-detention policy mandates that children should make such progress, and, unlike school starting age, there are no conflicting policy norms at the state level. 
Figure 3 shows the proportion of children with at least one instance of nonlinear progress across all 11 survey waves after the first entry into primary school. We categorize these movements as being sent back a grade, being held in a grade, or jumping forward an extra grade (e.g. from grade 1 directly to grade 3). Across all three states, only a minority of children follow a linear trajectory (as shown by the dotted white bar): at least three quarters experience at least one non-linear movement after entering primary school (as shown by the blue bars). In Telangana, roughly equal proportions of children are in each of the three non-linear categories. In Rajasthan and Assam, children are more likely to have repeated a grade than either jumping a grade or being sent back.

\section{Findings 2: In what ways does the timing of these transitions reflect parents' thinking about early childhood education?}

Between ages 4 and 8 then, few children are in the appropriate grade for age as per RTE norms, and fewer still experience a linear progression from one grade to the next. Similarly, among households interviewed for the study's qualitative component, only in a small minority (10 of 180) did the child enter in the appropriate age for grade and make linear progress. As shown in Table 3, the alternative experiences identified in the preceding section -being ahead, behind, sent back, repeating, or jumping a grade - were all represented. Through analysis of these interviews, this section helps explore the parental perceptions and institutional factors behind these observed trajectories.

[Table 3] 


\section{The idea that children below primary school age should attend an educational} institution is almost universally accepted, though not necessarily ECE.

Parental interviews across the three states find close to universal acceptance that young children below primary school-going age should be attending an educational institution rather than just staying at home, corroborating our earlier finding on young children's participation trajectories. But parents vary considerably in what they consider the best type of exposure for their young children.

Systematic governmental outreach initiatives emerge as important processes that shape parental attitudes with regard to the importance of ECE. The majority of parents interviewed in Telangana described participation in preschool as 'the usual path for young children'; all the parents who offered this explanation had sent their young children to a government anganwadi as the first step in their educational trajectories, and most explicitly mentioned the role of the ICDS anganwadi workers (AWWs) in shaping their view that participation in anganwadi was a prerequisite for enrolment in primary school. For example, outreach by the AWW tipped the balance for one mother in Telangana, who explained, 'he was small and I thought what he will do sitting in the home ... and teachers also had come to our house asking to send him to the anganwadi centre, so I sent him.' A similar pattern is seen in Assam, where about a third of parents mentioned being informed by AWWs that children ought to be sent to their local anganwadi centres. These parents often referred to the child's preschool as the 'allotted centre', indicating their awareness of the existence and purpose of the local anganwadi centres in the village.

In Rajasthan, in contrast, several parents spoke of how 'children [here] go directly to [grade] 1', echoing our quantitative finding that many children participated in primary school even at age 4. No parent in Rajasthan mentioned being influenced 
by AWWs or other kinds of outreach. On the contrary, many parents articulated a negative perception of anganwadis in terms of poor infrastructure, unsanitary environments and a perceived lack of 'useful activities' for young children. When private preschools were not affordable, primary schools were often seen as better options for these young children. This suggests that although the norm of young children's institutional participation is common across states, its expression varies.

\section{Parents usually viewed ECE as a downward extension of primary school}

Where differences between preschool-age and primary school-age children were discussed, these were commonly articulated in terms of children's physical, rather than age and developmentally appropriate cognitive, needs. For example, some parents mentioned children's health as a reason for limiting long-distance travel as 'kids get some illness when they are sent far from the home...I want him to study here [in a preschool nearby] until he becomes little older'. Similarly, in cases where children went to an anganwadi, most parents described the importance of a space where young children would be looked after while the parents worked. In the words of a mother from Telangana, 'he used to learn things there, sleep when he felt like sleeping and the teacher used to look after him even if we are little late coming back from the field.'

Beyond these physical and care related factors, parents' articulations of the desirable characteristics of preschools and primary schools were much the same. With the exception of just two parents who mentioned the importance of play, no parent mentioned characteristics of an ECE curriculum or teacher that were different from those that they used to describe primary schools. Parents of children who had attended private preschools often named, for example, factors such as English medium 
instruction; 'better discipline'; 'good quality teaching'; and 'studies given more importance'. More broadly, most parents mentioned strictly academic objectives 'to prepare for school' and 'to help with learning'. This is consistent with findings from a range of contexts globally (for example, Fung and Cheng 2012; Gamble, Ewing, and Wilhlem 2009; Kabay, Wolf, and Yoshikawa 2017; Qadiri and Manhas 2009; Xinyi and Tze-Peng 2015), which find that parents, especially those with lower education levels, prioritise academic and curricular preparation over more child-centred, informal learning. It is worth noting though that the exception to this trend occurred among recipients of targeted outreach activities: some of those parents in Telangana who had contact with AWWs articulated socialization and habituation as distinct purposes for ECE, suggesting that parental views are not immutable.

Even when the objectives of ECE and primary school were viewed as different, few parents visualized the ECE phase as requiring an environment and set of inputs distinct from those provided in primary school. The implications of this lack of differentiation are visible in the participation trajectories outlined earlier in this paper, and help explain why significant proportions of $4-5$ year olds were already in primary school, since parents often saw advantages rather than disadvantages in this early exposure to what children would have to learn later anyway. Given that policy documents' concern for providing appropriate environments for young children appears to be largely unfamiliar to parents in rural India, it is not surprising that parents' main considerations are practical ones, to do with children's physical readiness on the one hand and institutional willingness to allow their participation on the other. 
While the timing of a child's first entry into an educational institution is parentdependent, progression through the system is not. Non-linear progression is often the price of perceived 'better quality'.

The concept of 'age-appropriate' grades, so central to education policy, had little traction among interviewed parents. Within the qualitative sub-sample there are many cases of children going to anganwadi centres from age 2 onwards, although these centres are intended to offer ECE services to children only in the 3-6 age group. Similarly, many parents send their children to primary school even at age 4 , either because the school is the most convenient option or because early entry to school is perceived as getting a head start on learning.

Once in school, education policy mandates annual progress to the next grade without repetition, all the way through to the end of primary school at grade 8 . In practice, children's trajectories in the early years of education often entail grade repetitions, demotions or out-of-turn promotions, suggesting that not only parents but equally educational institutions fail to follow the 'age-appropriate grade' norm.

Parental interviews reveal that in several cases children first progressed to primary school only to be demoted again to preschool grades. For instance, in one case from Telangana, a child joined an anganwadi at age 3 and after one year was enrolled into a private preschool where he remained for three consecutive grades nursery, lower and upper kindergarten-thus only joining grade 1 at age 7, one year later than the RTE norm prescribes. In another case, the child first joined an anganwadi at age 3 and after two years progressed to a local government primary school where he studied for three years. However, his parents expressed dissatisfaction with the quality of education provided in the government school, commenting that 'although he did not study at all they used to promote him to a 
higher class'. The child was subsequently sent to a private school where he repeated two years of preschool before progressing to the primary grades in the same school thus repeating not only two years in preschool but also the first three grades of primary school.

We find similar cases in the other two states as well. In Assam, the reason many children remained in preschool for so long was due to changing centres at least once and repeating preschool grades in successive institutions. Also in Assam, a child who joined a government primary school was made to repeat grade 1 for two consecutive years after failing to pass in the annual examinations at school, despite the official no-detention policy. In Rajasthan, a child without any preschool exposure who joined a private school at age 4 was given an out of turn promotion to grade 2; according to the mother of the child, this was done at the suggestion of the school principal who believed that the child was a good student.

In several, if not all such cases, parents were aware of these non-linear trajectories and cognizant of the child's apparent learning difficulties or advantages; they usually accepted the judgement of the school or teacher and their decision to hold back, demote or promote the child. Changing schools, most often from government to private school but also on occasion from one private school to another, often involved grade repetition for the child - but far from being viewed as a problem, parents often interpreted grade repetition as an indicator of institutional quality, in the sense that a better-quality school was providing remedial education to a child who was not performing to the requisite level.

\section{Discussion}

Table 3 summarises our findings on ECE participation patterns and the key motivators underlying parents' decision-making in each state. These findings 
demonstrate the differing ways in which families across rural India approach young children's educational needs and their perspectives on early childhood education. In Telangana, for instance, there was a positive perception among parents in the subsample regarding the importance of preschool; preschool education was considered important not only to habituate and socialise young children but also to teach them critical skills for school. These articulations are missing in the interviews with parents in Assam and Rajasthan. In Rajasthan particularly, we find an absence of community awareness with respect to ECE and its importance for young children as well as a poor perception of anganwadis in general.

\section{[Table 4]}

Perhaps the clearest implication of these findings is that federal mandates on participation in ECE and primary schooling are largely ignored in rural India, both by parents and by educational institutions. Only a minority of children in our sample follow RTE norms on the age at which children should move through ECE and early primary grades. This should not be misconstrued though as households simply following state policy mandates instead: in each state, there are both many children behind and many children ahead of RTE norms, meaning that most are not following state norms either.

In terms of influencing household practices, a factor that appears more impactful than central government mandates is outreach by local service providers. A strong community awareness program, stressing the importance and appropriateness of early education for young children, can go a long way in creating understanding of and 'demand' for ECE among parents, whether in the government or private sector. Telangana shows that this can be especially influential when the focus is not just normalising ECE participation, but also disseminating awareness of its value to 
children's development. Of course, outreach alone is not sufficient: it is equally important that anganwadis, the largest preschool network in India, are functional with staff and appropriate infrastructure so that parents are convinced of the value of sending their children to these institutions.

As shown, the causes of non-linear progress through the school grades are manifold. Perhaps the most pertinent factor for policy and practice is that instances of non-linear progress tend to be instigated by schools rather than parents. A common reason is the reportedly higher standard followed by private schools that often require children to repeat grades that they have already completed in a government institution. This raises important questions about policy implementation on the ground, given that these practices are not permitted by law. In most such cases, when parents accept the decision of the schools and teachers, this is partly a reflection of the power imbalance between parents and schools, but often also an expression of parents' belief in the superiority of private schools and consequent willingness to adhere to their decisions.

Elements of ECE programmes that are distinctive from primary school education, deemed by both international research and national policy to be important indicators of high-quality ECE, are completely absent from parents' conceptualizations of quality. Moreover, the fact that in two of the three states large numbers of underage children were participating in primary schools suggests that schools themselves may be knowingly or unknowingly complicit in contributing to parental perceptions that ECE is merely a downward extension of primary school. Although mechanisms to regulate what ECE providers offer to young children are important to put in place, the evidence presented in this study suggests that without strong efforts to convince both service providers and parents of the fact that teaching 
the 3Rs to young children is detrimental to the latter's development, regulation alone is unlikely to transform practice on the ground. 


\section{References}

Ade, Anju, Subodh S Gupta, Chetna Maliye, Pradeep R Deshmukh, and Bishan S Garg. 2010. "Effect of improvement of pre-school education through Anganwadi center on intelligence and development quotient of children." The Indian Journal of Pediatrics 77 (5):541-546.

Alcott, Benjamin, and Pauline Rose. 2015. "Schools and learning in rural India and Pakistan: Who goes where, and how much are they learning?" Prospects 45 (3):345-363.

Ali, Shaik Liyakhath. 2015. "Right to Education (RTE) in Context with Pre-schooling (ECCE)." International Journal of Innovative Research and Development 4 (10).

Allison, Paul. 2012. Missing data. Thousand Oaks: Sage.

ASER Centre. 2017. Annual status of education report (rural) 2016. New Delhi: ASER Centre.

ASER Centre. 2015. Trends over time 2006-2014; a supplement to the Annual Status of Education Report. New Delhi: ASER Centre.

Ashley, Laura Day, Claire Mcloughlin, Monazza Aslam, Jakob Engel, Joseph Wales, Shenila Rawal, Richard Batley, Geeta Kingdon, Susan Nicolai, and P Rose. 2014. "The role and impact of private schools in developing countries." Rigorous Literature Review.

Becker, Gary Stanley. 1975. Human capital: A theoretical and empirical analysis, with special reference to education (Human behavior and social institutions). New York: National Bureau of Economic Research.

Bhattacharjea, Suman, Rukmini Banerji, and Wilima Wadhwa. 2011. Inside Primary Schools: Teaching and Learning in Rural India. New Delhi: ASER Centre 
Borooah, Vani K. 2012. "Social identity and educational attainment: the role of caste and religion in explaining differences between children in India." Journal of Development Studies 48 (7):887-903.

Braun, Virginia, and Victoria Clarke. 2006. "Using thematic analysis in psychology." Qualitative research in psychology 3 (2):77-101.

Campbell, Frances A, Elizabeth P Pungello, Shari Miller-Johnson, Margaret Burchinal, and Craig T Ramey. 2001. "The development of cognitive and academic abilities: growth curves from an early childhood educational experiment." Developmental psychology 37 (2):231.

Cunha, Flavio, James J Heckman, Lance Lochner, and Dimitriy V Masterov. 2006. "Interpreting the evidence on life cycle skill formation." Handbook of the Economics of Education 1:697-812.

Educational Initiatives. 2010. Student Learning Study: Status of Student Learning across 18 States of India in Urban and Rural Schools. Ahmedabad: Education Initiatives.

Engle, Patrice L, Lia CH Fernald, Harold Alderman, Jere Behrman, Chloe O'Gara, Aisha Yousafzai, Meena Cabral de Mello, Melissa Hidrobo, Nurper Ulkuer, and Ilgi Ertem. 2011. "Strategies for reducing inequalities and improving developmental outcomes for young children in low-income and middleincome countries." The Lancet 378 (9799):1339-1353.

Fung, Chanel Kit Ho, and Doris Pui Wah Cheng. 2012. "Consensus or dissensus? Stakeholders' views on the role of play in learning." Early Years 32 (1):1733.

Gamble, Wendy C, Allison R Ewing, and Mari S Wilhlem. 2009. "Parental perceptions of characteristics of non-parental child care: Belief dimensions, 
family and child correlates." Journal of Child and Family Studies 18 (1):7082.

Government of India, Ministry of Human Resource Development. 2014. Selected Information on School Education 2011-12. New Delhi: Government of India Press

Government of India, Ministry of Law and Justice. 2009. The Right of Children to Free and Compulsory Education Act. New Delhi: Government of India Press

Government of India, Ministry of Women and Child Development. 2013a. National Early Childhood Care and Education Policy. New Delhi: Government of India.

Government of India, Ministry of Women and Child Development. 2013b. Potential Good Practices: the ICDS Experience. New Delhi: Government of India

Government of India, Ministry of Women and Child Development. 2017. "Integrated Child Development Services (ICDS) Scheme.” Integrated Child Development Services (ICDS) Scheme. Accessed 29 June 2018. icdswcd.nic.in/icds/icds.aspx

Greene, Jennifer C. 2007. Mixed methods in social inquiry. Vol. 9: John Wiley \& Sons.

Heckman, James J. 2011. "The Economics of Inequality: The Value of Early Childhood Education." American Educator 35 (1):31.

Kabay, Sarah, Sharon Wolf, and Hirokazu Yoshikawa. 2017. "“So that his mind will open": Parental perceptions of early childhood education in urbanizing Ghana." International Journal of Educational Development 57:44-53. 
Karoly, Lynn. A., P.W. Greenwood, S.S. Everingham, J. Hoube, M.R. Kilburn, C.P. Rydell, and J. Chiesa. (1998). What We Know and Don't Know About the Benefits of Early Childhood Intervention. Santa Monica:RAND Corporation. Kingdon, Geeta Gandhi. 2007. "The progress of school education in India." Oxford Review of Economic Policy 23 (2):168-195.

Kohlberg, Lawrence. 1968. "Early education: A cognitive-developmental view." Child development:1013-1062.

Mehta, Arun C. 2007. Student Flow at Primary Level: A Study based on DISE Data. New Delhi: National University of Educational Planning and Administration. Nair, MKC, Elsie Philip, L Jeyaseelan, Babu George, Suja Mathews, and K Padma. 2009. "Effect of Child Development Centre model early stimulation among at risk babies--a randomized controlled trial.” Indian Pediatrics46:S20-S26..

Nonoyama-Tarumi, Yuko, Edilberto Loaiza, and Patrice Engle. 2009. "Inequalities in attendance in organized early learning programmes in developing societies: findings from household surveys." Compare 39 (3):385-409.

Piramal, Reshma, and James Law. 2001. "Evaluating a programme to enhance vocabulary development in pre-schoolers." International journal of language \& communication disorders 36 (S1):222-227.

Pritchett, Lant, and Amanda Beatty. 2015. "Slow down, you're going too fast: Matching curricula to student skill levels." International Journal of Educational Development 40:276-288.

Programme Evaluation Organisation (PEO) Planning Commission. 2011. Evaluation Report on Integrated Child Development Services. New Delhi: Government of India. 
Qadiri, Fouziya, and Sarika Manhas. 2009. "Parental perception towards preschool education imparted at early childhood education centers." Studies on Home and Community Science 3 (1):19-24.

Ramey, SL. 1998. "Early intervention and early experience." American Psychologist 53 (2):109-120.

Rao, N., J. Sun, J. Wong, B. Weekes, P. Ip, S. Shaeffer, M. Young, M. Bray, E. Chen, and D. Lee. 2013. Early Childhood Development and Cognitive Development in Developing Countries: A Rigorous Literature Review. London: DFID.

Reddy, Anugula N, and Shantha Sinha. 2010. School Dropouts or Pushouts? Overcoming Barriers for the Right to Education. New Delhi: National University of Educational Planning and Administration.

Registrar of India. 2011. “Census of India 2011.”Registrar of India. Accessed 29 June 2018. http://censusindia.gov.in/

Rolleston, Caine, and Zoe James. 2015. "After access: Divergent learning profiles in Vietnam and India." Prospects 45 (3):285-303.

Rose, Pauline Margaret, Ricardo Sabates, Benjamin Matthew Alcott, and Ioana Sonia Ilie. 2017. Overcoming inequalities within countries to achieve global convergence in learning. Background paper for The International Commission on Financing Global Education Opportunity. Retrieved from http://report.educationcommission.org/download/829/

Shore, Rima. 1997. Rethinking the brain: New insights into early development.New York: Families and Work Institute

Singh, Renu, and Colin Bangay. 2014. "Low fee private schooling in India-More questions than answers? Observations from the Young Lives longitudinal 
research in Andhra Pradesh." International Journal of Educational Development 39:132-140.

Small, Mario Luis. 2011. "How to conduct a mixed methods study: Recent trends in a rapidly growing literature." Annual review of sociology 37.

Streuli, Natalia, Uma Vennam, and Martin Woodhead. 2011. Increasing choice or inequality? Pathways through early education in Andhra Pradesh, India. The Hague: Bernard van Leer.

UNESCO. 2015. Thematic Indicators to Monitor the Education 2030 Agenda. Paris: UNESCO.

United Nations. 2010. The Millennium Development Goals Report. United Nations: New York.

Woodhead, Martin, Patricia Ames, Uma Vennam, Workneh Abebe, and Natalia Streuli. 2009. Equity and quality? Challenges for early childhood and primary education in Ethiopia, India and Peru. The Hague: Bernard van Leer.

Woodhead, Martin, Paul Dornan, and Helen Murray. 2013. What inequality means for children: Evidence from Young Lives. Oxford: Young Lives.

Woodhead, Martin, Imogen Feathersone, Laura Bolton, and Penny Robertson. 2014. Early Childhood Development: Delivering Inter-sectoral Policies, Programmes and Services in Low-resource Settings. Oxford: Health \& Education Advice \& Resource Team (HEART).

Woodhead, Martin, Melanie Frost, and Zoe James. 2013. "Does growth in private schooling contribute to Education for All? Evidence from a longitudinal, two cohort study in Andhra Pradesh, India." International Journal of Educational Development 33 (1):65-73. 
Xinyi, Yong Deborah, and Wong Tze-Peng. 2015. "Bridging the Research and Cultural-Practice Gap in Early Language Intervention in Malaysia." Jurnal Sains Kesihatan Malaysia (Malaysian Journal of Health Sciences) 13 (2). Young, Mary E, and Linda M Richardson. 2007. Early child development from measurement to action: a priority for growth and equity. Washington DC: World Bank Publications. 
Table 1: Summary statistics for study sample

\begin{tabular}{|c|c|c|c|}
\hline & Assam & Telangana & Rajasthan \\
\hline \multicolumn{4}{|l|}{ Percentage of children... } \\
\hline whose home language is same as official state language & 52 & 88 & 18 \\
\hline whose mother has never been to school & 33 & 47 & 58 \\
\hline whose mother completed Grade 5 & 52 & 45 & 39 \\
\hline who had reading material at home in survey wave 1 & 86 & 84 & 53 \\
\hline with at least one government ECE provider in village & 100 & 100 & 100 \\
\hline with three or more government ECE providers in village & 100 & 100 & 100 \\
\hline with at least one private ECE provider in village & 82 & 76 & 64 \\
\hline \multirow[t]{2}{*}{ with three or more private ECE providers in village } & 29 & 39 & 93 \\
\hline & 2,140 & 3,074 & 2,122 \\
\hline
\end{tabular}


Table 2: Participation categories at average age 5 (wave 3)

\begin{tabular}{llll}
\hline & Assam & Rajasthan & Telangana \\
\hline Have participated in pre-primary (\%) & 100 & 80 & 92 \\
Have participated in primary school $(\%)$ & 4 & 51 & 51 \\
& $\mathrm{~N}=2,140$ & 3,074 & 2,122 \\
\hline
\end{tabular}


Table 3: Enrolment patterns among interviewed households

\begin{tabular}{lccccc}
\hline & Linear & Repeat & $\begin{array}{c}\text { Sent } \\
\text { back }\end{array}$ & $\begin{array}{c}\text { Jump } \\
\text { grade }\end{array}$ & Total \\
\hline Ahead, i.e., early transition to primary school & 13 & 38 & 25 & 25 & 101 \\
On time transition to primary school & 10 & 14 & 5 & 23 & 52 \\
Behind, i.e., late transition to primary school & 9 & 12 & 1 & 5 & 27 \\
Total & 32 & 64 & 31 & 53 & 180 \\
\hline
\end{tabular}


Table 4: Summary of findings for each state

\begin{tabular}{|c|c|c|}
\hline & Patterns(research question 1) & Motivations (research question 2) \\
\hline Telangana & $\begin{array}{l}\text { - At age 4, most children are in the } \\
\text { appropriate grade for age, with } \\
\text { near universal participation in } \\
\text { ECE. } \\
\text { - Many children enter primary } \\
\text { school at age 5, thereby moving } \\
\text { 'ahead' of track relative to } \\
\text { national RTE norms. } \\
\text { - Once in primary school, about a } \\
\text { quarter of children have at least } \\
\text { one experience of being sent back } \\
\text { to a lower grade. }\end{array}$ & $\begin{array}{l}\text { - Sending young children to } \\
\text { preschool is a norm. } \\
\text { - Strong community awareness } \\
\text { systems through the efforts of } \\
\text { anganwadi workers and school } \\
\text { teachers contribute to this } \\
\text { understanding. } \\
\text { - Grade demotions and repetitions } \\
\text { are accepted by parents as } \\
\text { indicating appropriate institutional } \\
\text { concern for children's learning. }\end{array}$ \\
\hline Assam & $\begin{array}{l}\text { - } \begin{array}{l}\text { Near universal enrolment in } \\
\text { preschool at age } 4 .\end{array} \\
\text { - Children spend longer in } \\
\text { preschool than stipulated by RTE } \\
\text { norms, so most enter primary } \\
\text { school 'late' - at age } 7 \text { or } 8 \text {. } \\
\text { - Close to half of children repeat a } \\
\text { grade after they make the first } \\
\text { transition to primary school. }\end{array}$ & $\begin{array}{l}\text { - Sending young children to } \\
\text { preschool is a community norm. } \\
\text { - This acceptance is aided by the } \\
\text { community awareness work } \\
\text { undertaken by anganwadi workers } \\
\text { - Grade repetition in both ECE and } \\
\text { primary school is an accepted } \\
\text { practice when children change } \\
\text { institutions. }\end{array}$ \\
\hline Rajasthan & $\begin{array}{l}\text { - Many children do not participate } \\
\text { in any institution at age } 4 . \\
\text { - } \text { Many children are attending } \\
\text { primary school at age } 4 . \\
\text { - Grade repetitions in primary } \\
\text { school are quite common; } 35 \% \text { of } \\
\text { children experienced at least one. }\end{array}$ & $\begin{array}{l}\text { - Community awareness of the } \\
\text { importance of ECE largely } \\
\text { missing. } \\
\text { - Outreach by anganwadi workers } \\
\text { infrequent or absent. } \\
\text { - Poor perception of anganwadi } \\
\text { centres due to poor infrastructure } \\
\text { in centres. } \\
\text { - Children able to participate in } \\
\text { primary school without prior ECE, } \\
\text { even at age } 4 \text {. }\end{array}$ \\
\hline
\end{tabular}


Figure 1: The three states sampled: (from west to east) Rajasthan, Telangana, and Assam

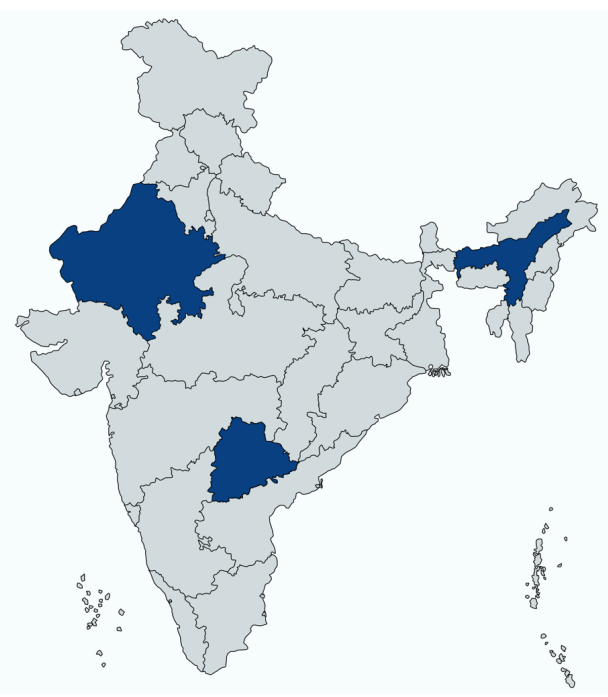


Figure 2: Proportion of children who are in the appropriate grade for age, by age and state
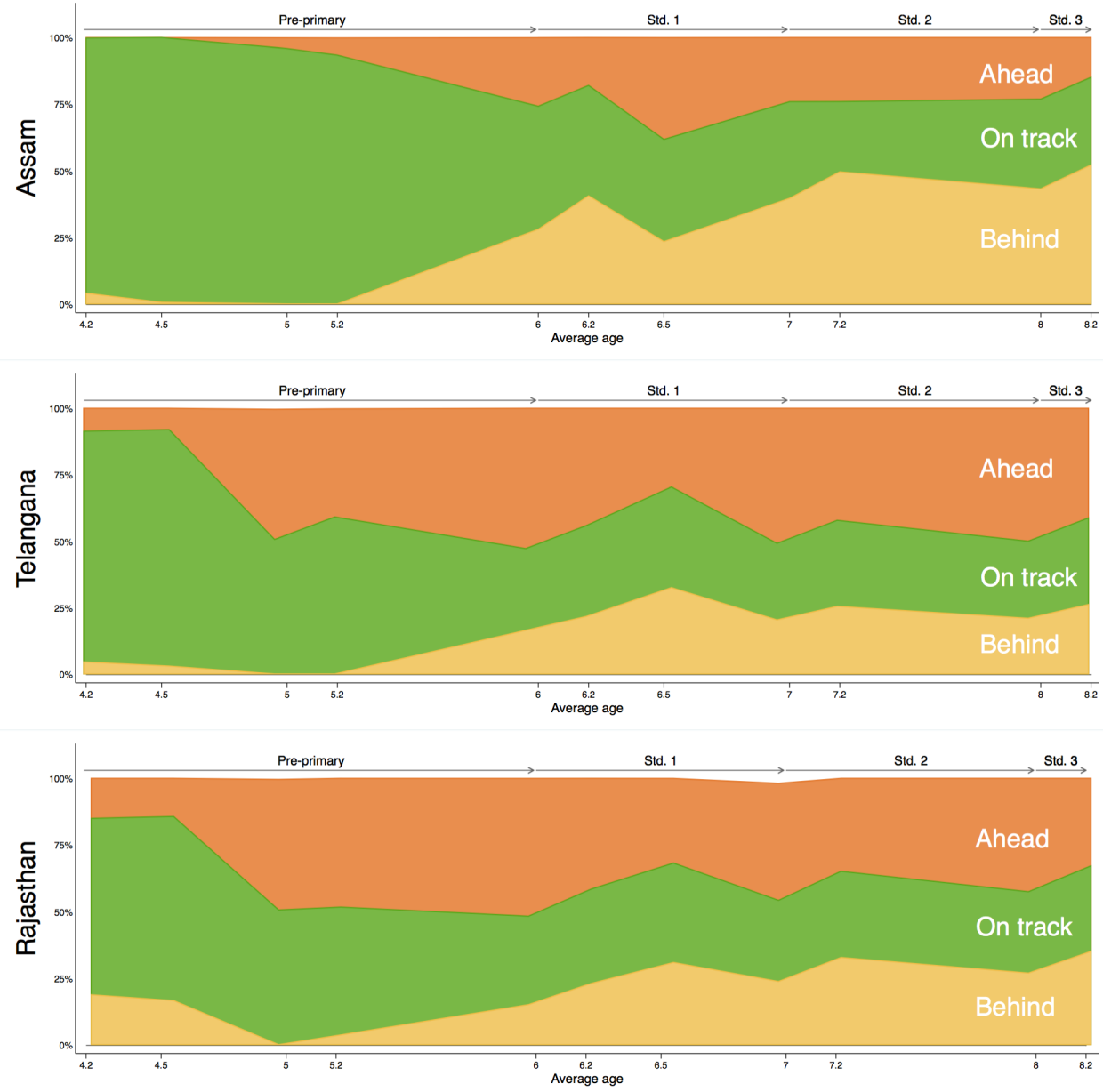
Figure 3: First non-linear grade movement after first entry to primary school, by state

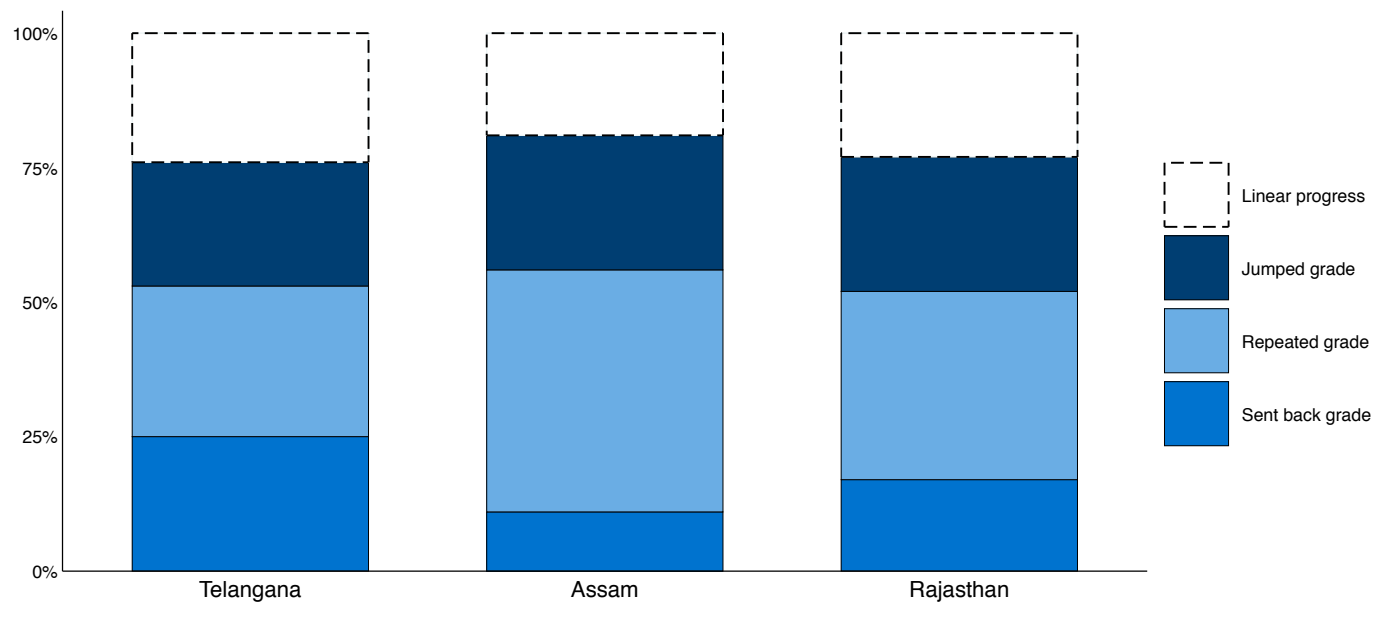

Note: This figure depicts the first instance of non-linear grade movement after children transition to primary school for the first time. Many of the children may have multiple instances of non-linear grade movement. 